\title{
Investigating the Evidence of the Real-Life Impact of Acute Hyperglycaemia
}

\author{
Simon Heller · Natalie Houwing • Nana Kragh • Uffe Jon Ploug • \\ Annie Nikolajsen · Cathelijne J. M. Alleman
}

To view enhanced content go to www.diabetestherapy-open.com

Received: June 19, 2015 / Published online: August 4, 2015

(C) The Author(s) 2015. This article is published with open access at Springerlink.com

\begin{abstract}
Poorly controlled diabetes mellitus $(\mathrm{DM})$ is associated with the development of long-term micro- and macro-vascular complications. The predominant focus of anti-diabetic therapy has been on lowering glycosylated haemoglobin levels, with a strong emphasis on fasting plasma glucose (particularly in Type $2 \mathrm{DM}$ ). There is considerable evidence indicating that post-meal hyperglycaemic levels are independently associated with higher risks of macro-vascular disease. Although some have identified mechanisms which may account for these observations, interventions which have specifically targeted postprandial glucose rises showed little or no effect in reducing cardiovascular risk. Clinical experience and some recent studies suggest acute
\end{abstract}

Electronic supplementary material The online version of this article (doi:10.1007/s13300-015-0126-y) contains supplementary material, which is available to authorized users.

S. Heller

The University of Sheffield, Sheffield, UK

N. Houwing · C. J. M. Alleman ( $\varangle)$

Pharmerit BV, Rotterdam, The Netherlands

e-mail: calleman@pharmerit.com

N. Kragh · U. J. Ploug · A. Nikolajsen

Novo Nordisk A/S, Søborg, Denmark hyperglycaemia affects cognition and other indicators of performance, equivalent to impairment seen during hypoglycaemia. In this brief report, we evaluated the published studies and argue that acute hyperglycaemia is worth investigating in relation to the real-life implications. In summary, evidence exists suggesting that acute hyperglycaemia may lead to impaired cognitive performance and productivity, but the relationship between these effects and daily activities remains poorly understood. Further research is required to enhance our understanding of acute hyperglycaemia in daily life. A better appreciation of clinically relevant effects of acute hyperglycaemia will allow us to determine whether it needs to be addressed by specific treatment.

Funding: Novo Nordisk A/S Søborg, Denmark.

Keywords: Acute; Hyperglycaemia; Real life; Short term

\section{BRIEF REPORT}

Poorly controlled diabetes mellitus (DM) is associated with the development of long-term 
micro- and macro-vascular complications [1-6]. The predominant focus of anti-diabetic therapy has been on lowering glycosylated haemoglobin (HbA1c) levels, with a strong emphasis on fasting plasma glucose [particularly in Type 2 DM (T2DM)]. There is considerable epidemiological evidence indicating that post-meal hyperglycaemic levels are independently associated with higher risks of macro-vascular disease [1]. Although some have identified mechanisms which may account for these observations, interventions which have specifically targeted postprandial glucose rises showed little or no effect in reducing cardiovascular risk [7-10]. Clinical experience and some recent studies [11-15] suggest acute hyperglycaemia affects cognition and other indicators of performance, equivalent to impairment seen during hypoglycaemia. In this brief report, we review the published studies and argue that acute hyperglycaemia is worth investigating in relation to the real-life implications. Throughout this review the term acute hyperglycaemia is mostly used, although there is no clear definition available for this term. As acute hyperglycaemia itself is not a clear terminology other sources might refer to this concept as (high) postprandial, glucose spikes and post-challenge or short-term hyperglycaemia/glucose. The analysis in this article is based on previously conducted studies, and does not involve any new studies of human or animal subjects performed by any of the authors.

Acute hyperglycaemia causes symptoms of increased thirst, urination, hunger and weight loss [16]. Children with T1DM as well as their parents describe negative effects of hyperglycaemia including nausea, tiredness, loss of temper, thirst, weakness and headaches [11]. Although these physical symptoms might go unnoticed acute hyperglycaemia could have significant impact on cognitive performance and mood. Recent experimental studies which have investigated the relationship between high blood glucose (BG) level and cognitive function provide evidence of the potential effect of acute hyperglycaemia [12-15]. Sommerfield et al. [15] examined the effects of clamped hyperglycaemia (297 mg/dL/16.5 mmol/L) on cognitive function and mood states and found that in subjects blind to their blood glucose, speed of information processing, working memory and aspects of attention were significantly impaired. Mood was also adversely affected by acute hyperglycaemia, including increased feelings of agitation and anxiety, increased feelings of tiredness and lethargy and decreased feelings of happiness. Cox et al. [12] used a hand-held computer which required participants with DM to undertake a series of simple cognitive tests before measuring their BG. They demonstrated that at a $B G>270 \mathrm{mg} / \mathrm{dL}(15 \mathrm{mmol} / \mathrm{L})$, verbal fluency and subtraction time slowed in individuals with T1DM (significantly; additional $1.7-3 \mathrm{~s}$ per subtraction). In persons with T2DM all tests were significantly slowed during hyperglycaemia (>270 mg/dL).

These changes have the potential to impair patient well-being, daily activities and productivity. For example, the performance of DM patients at work or children taking tests at school might be affected during a hyperglycaemic episode. Individuals at work or school often choose to maintain a relatively high BG level to prevent hypoglycaemia [14]. Yet, if short-term effects of acute hyperglycaemia are significant, this strategy may be counterproductive. Acute hyperglycaemia may have additional (in)direct costs, reflected in increased doctor's visits and lost productivity.

It is difficult to be sure to what extent impaired cognitive function measured by experimental tests reflect real-life activities. 
Although the studies described above provide valid evidence of the effect of hyperglycaemia on cognitive function and mood, they were not specifically designed to measure the direct impact of these events on daily activities such as driving and performance at school or during tests. Importantly, in both the studies of Sommerfield et al. [15] and Cox et al. [12], individuals were blind to their $\mathrm{BG}$ at the time their performance was measured. This increases the likelihood that the measured alteration in mood and impaired performance are a direct result of the acute increase in BG. Furthermore, the observation that impaired performance was equivalent to that observed during (acute) hypoglycaemia suggests that the changes observed may be clinically relevant.

To establish the importance of acute rises in BG, further (real-world) research is required, as this evidence is currently unavailable. Further research can establish whether acute hyperglycaemia impairs daily activities such as working, driving and school performance. Studies should also explore the level of BG above which performance is impaired to determine the BG range which impairs cognitive functioning. Published guidelines propose that patients aim for BG values below 160 or $180 \mathrm{mg} / \mathrm{dL}$ to prevent long-term complications but it is unclear if this threshold also applies to the short-term effects [1].

Future research might involve the use of driving simulators or 'real-life' examinations, experimental approaches which have been used in the study of hypoglycaemia and which have provided important clinical guidance to both professional caretakers and patients. Mood, patient well-being, productivity and resource use may also be assessed by patient-reported outcome measures. Simultaneous BG levels can be measured either by self-monitored blood glucose (SMBG) or continuous glucose monitoring
(CGM). Most patients and their carers continue to rely on SMBG, but its inability to identify whether glucose levels are rising or falling means that the information it provides is relatively incomplete and it is difficult to compare data across patients. SMBG is also unable to reliably detect hyperglycaemic unawareness and nocturnal hypoglycaemia compared to CGM. CGM offers continuous glucose data with regular intervals to adjust insulin therapy and to monitor lifestyle intervention. As CGM measures the BG value throughout the day it is more likely to identify episodes of acute hyperglycaemia and the time spent in a hyperglycaemic state [17]. In the last few years, the accuracy, precision, stability, reliability and availability of CGM is approaching SMBG and laboratory measurements [18]. Subjects should be blinded to their BG value, when completing assignments and questionnaires, to prevent outcomes to be negatively affected by patient mood changes resulting from seeing a BG value they regard as undesirable.

\section{CONCLUSION}

Evidence exists suggesting that acute hyperglycaemia may lead to impaired cognitive performance and productivity, but the relationship between these effects and daily activities remains poorly understood. Further research is required to enhance our understanding of acute hyperglycaemia in daily life. A better appreciation of clinically relevant effects of acute hyperglycaemia will allow us to determine whether it needs to be addressed by specific treatment.

\section{ACKNOWLEDGMENTS}

Sponsorship and article processing charges for this study were funded by Novo Nordisk A/S 
Søborg, Denmark. The authors would like to thank Dr. Weiwei Xu MD, employee at Pharmerit during the development of the manuscript, for her contribution to the manuscript as medical writer. Support for this assistance was funded by Novo Nordisk A/S. All named authors meet the International Committee of Medical Journal Editors (ICMJE) criteria for authorship for this manuscript, take responsibility for the integrity of the work as a whole, and have given final approval for the version to be published.

Conflict of interest. Simon Heller participated in this research as an employee of The University of Sheffield.

Natalie Houwing is a current employee of Pharmerit and participated in this research during their employment at Pharmerit.

Nana Kragh is a current employee and shareholder of Novo Nordisk and participated in this research during their employment at Novo Nordisk.

Uffe Jon Ploug is a current employee and shareholder of Novo Nordisk and participated in this research during their employment at Novo Nordisk.

Annie Nikolajsen is a current employee of Novo Nordisk and participated in this research during their employment at Novo Nordisk.

Cathelijne Alleman is a current employee of Pharmerit and participated in this research during their employment at Pharmerit.

All authors had final control over the content, review and submission of the manuscript.

Compliance with ethics guidelines. The analysis in this article is based on previously conducted studies, and does not involve any new studies of human or animal subjects performed by any of the authors.
Open Access. This article is distributed under the terms of the Creative Commons Attribution-NonCommercial 4.0 International License (http://creativecommons.org/licenses/ by-nc/4.0/), which permits any noncommercial use, distribution, and reproduction in any medium, provided you give appropriate credit to the original author(s) and the source, provide a link to the Creative Commons license, and indicate if changes were made.

\section{REFERENCES}

1. International Diabetes Federation (IDF). Guideline for Management of PostMeal Glucose in Diabetes; 2011.

2. The effect of intensive treatment of diabetes on the development and progression of long-term complications in insulin-dependent diabetes mellitus. The Diabetes Control and Complications Trial Research Group. N Engl J Med. 1993;329(14): 977-86.

3. Ohkubo Y, Kishikawa H, Araki E, Miyata T, Isami S, Motoyoshi S, Kojima Y, Furuyoshi N, Shichiri M. Intensive insulin therapy prevents the progression of diabetic microvascular complications in Japanese patients with non-insulin-dependent diabetes mellitus: a randomized prospective 6-year study. Diabetes Res Clin Pract. 1995;28(2):103-17.

4. Intensive blood-glucose control with sulphonylureas or insulin compared with conventional treatment and risk of complications in patients with type 2 diabetes (UKPDS 33). UK Prospective Diabetes Study (UKPDS) Group. Lancet. 1998;352(9131):837-53.

5. Effect of intensive blood-glucose control with metformin on complications in overweight patients with type 2 diabetes (UKPDS 34). UK Prospective Diabetes Study (UKPDS) Group. Lancet. 1998;352(9131):854-65.

6. Huxley R, Barzi F, Woodward M. Excess risk of fatal coronary heart disease associated with diabetes in men and women: meta-analysis of 37 prospective cohort studies. BMJ. 2006;332(7533):73-8.

7. Gerstein HC, Miller ME, Byington RP, Goff DC, Bigger JT, Buse JB, Cushman WC, Genuth S, Ismail-Beigi F, Grimm RH, Probstfield JL, Simons-Morton DG, Friedewald WT. Effects of 
intensive glucose lowering in type 2 diabetes. N Engl J Med. 2008;358(24):2545-59.

8. Patel A, MacMahon S, Chalmers J, Neal B, Billot L, Woodward M, Marre M, Cooper M, Glasziou P, Grobbee D, Hamet P, Harrap S, Heller S, Liu L, Mancia G, Mogensen CE, Pan C, Poulter N, Rodgers A, Williams B, Bompoint S, de Galan BE, Joshi R, Travert F. Intensive blood glucose control and vascular outcomes in patients with type 2 diabetes. N Engl J Med. 2008;358(24):2560-72.

9. Duckworth W, Abraira C, Moritz T, Reda D, Emanuele N, Reaven PD, Zieve FJ, Marks J, Davis SN, Hayward R, Warren SR, Goldman S, McCarren M, Vitek ME, Henderson WG, Huang GD. Glucose control and vascular complications in veterans with type 2 diabetes. N Engl J Med. 2009;360(2):129-39.

10. Holman RR, Paul SK, Bethel MA, Matthews DR, Neil HAW. 10-year follow-up of intensive glucose control in type 2 diabetes. $\mathrm{N}$ Engl $\mathrm{J}$ Med. 2008;359(15):1577-89.

11. Martin DD, Davis EA, Jones TW. Acute effects of hyperglycaemia in children with type 1 diabetes mellitus: the patient's perspective. J Pediatr Endocrinol Metab. 2006;19(7):927-36.

12. Cox DJ, Kovatchev BP, Gonder-Frederick LA, Summers KH, McCall A, Grimm KJ, Clarke WL. Relationships between hyperglycemia and cognitive performance among adults with type 1 and type 2 diabetes. Diabetes Care. 2005;28(1):71-7.
13. Cox D, Gonder-Frederick L, McCall A, Kovatchev B, Clarke W. The effects of glucose fluctuation on cognitive function and QOL: the functional costs of hypoglycaemia and hyperglycaemia among adults with type 1 or type 2 diabetes. Int J Clin Pract. 2002;(Suppl. no. 129):20-6.

14. Gonder-Frederick LA, Zrebiec JF, Bauchowitz AU, Ritterband LM, Magee JC, Cox DJ, Clarke WL. Cognitive function is disrupted by both hypo- and hyperglycemia in school-aged children with type 1 diabetes: a field study. Diabetes Care. 2009;32(6): 1001-6.

15. Sommerfield AJ, Deary IJ, Frier BM. Acute hyperglycemia alters mood state and impairs cognitive performance in people with type 2 diabetes. Diabetes Care. 2004;27(10):2335-40.

16. World Health Organization (WHO), "About diabetes," 2013. [Online]. http://www.who. int/diabetes/action_online/basics/en/index.html. Accessed Sept 5, 2014.

17. Poolsup N, Suksomboon N, Kyaw AM. Systematic review and meta-analysis of the effectiveness of continuous glucose monitoring (CGM) on glucose control in diabetes. Diabetol Metab Syndr. 2013;5(1):39.

18. Rodbard D. The challenges of measuring glycemic variability. J Diabetes Sci Technol. 2012;6(3):712-5. 